REVIEW

\title{
Investigating perinatal death: a review of the options when autopsy consent is refused
}

\author{
C Wright, R E J Lee
}

Arch Dis Child Fetal Neonatal Ed 2004;89:F285-F288. doi: 10.1136/adc.2003.022483

Autopsy remains the best method of investigating perinatal deaths. Recent years have, however, seen a decline in autopsy rates. This review looks at some of the options available for investigating perinatal deaths when the family decline to give consent for standard autopsy.

See end of article for authors' affiliations ....................

Correspondence to: Dr Wright, Department of Pathology, Royal Victoria Infirmary, Newcastle upon Tyne NE1 4LP, UK; christopher.wright@ ncl.ac.uk

Accepted 25 June 2003
$\mathrm{T}$ he information provided by perinatal autopsy has important implications both for families and for maintaining standards of care, ${ }^{1}$ and remains the best method of investigating fetal loss, stillbirth, and neonatal death. There has been a gradual fall in autopsy rates in recent years, and the reasons for this probably include changing cultural and societal views towards death, the body of the deceased, and the autopsy procedure itself and a decline in healthcare professionals' understanding of the value of the autopsy. ${ }^{2}{ }^{3}$ The recent controversies surrounding the issue of organ retention are also likely to have had an impact. Nonetheless, recent national figures show autopsy rates for stillbirths of $58 \%$ and neonatal deaths of $41 \%$, which are considerably higher than those for adults and reflect a continuing recognition of the important benefits of the procedure in the perinatal period.

The standard perinatal autopsy allows identification of a huge range of fetal and neonatal disorders. The focus of the investigation is tailored to the particular clinical circumstances, but the basic methods available in all cases include:

- External examination of the baby

- Examination of the internal organs

- Examination of the placenta and cord

- Imaging

- Supplementary laboratory investigations such as microbiology and cytogenetics

- Metabolic studies

Although internal organ examination represents only one step in the process, its importance lies in the fact there is currently no other way of reliably obtaining the detailed and crucial information it provides. This comes in particular from:

- Internal organ weights. These allow accurate assessment of intrauterine growth restriction, organomegaly syndromes-for example, diabetes-and disordered growth of individual organs.

- Detailed macroscopic and histological examination of internal organs. Clearly, direct macroscopic examination of the organs permits detection of major malformations, iatrogenic disease, etc. The diagnosis of infection, assessment of hypoxic injury (particularly of the brain), and identification of many types of malformation/dysplasia and metabolic disease are largely dependent on histology. A combination of macroscopic (cerebral gyral pattern) and histological (lung, kidney) appearances is used to aid assessment of gestational age.

Clearly, for many of those families not willing to give consent to a standard autopsy their major objection is to this invasive step of internal organ examination. However, this should not necessarily preclude any postmortem investigation as other options are available, and, although none can replace the standard autopsy, they may provide useful information. In addition to limiting the autopsy to particular organs or body cavities, these options include the non-invasive components of the standard postmortem examination (external and placental examination and radiology) and other methods for assessing internal organ morphology, such as magnetic resonance imaging (MRI) and needle biopsy. The aim of this article is to review the potential benefits of these non-invasive or less invasive methods of investigation.

\section{EXTERNAL EXAMINATION}

Many non-pathologists are unaware of the importance of detailed external examination after perinatal loss. In addition to assessment of gestational age from basic external measurements ${ }^{5}$ and identification of dysmorphic features, a large range of other features can be evaluated. These include: nutritional status-for example, growth restriction or macrosomia; degree of autolysis (timing of intrauterine death); odour (presence of infection); soft tissue oedema (generalised, localised); pallor-for example, fetomaternal bleeding; the presence of meconium staining, jaundice, petechiae; traumatic and other iatrogenic lesions. If a perinatal pathologist or clinical geneticist is not immediately available, abnormalities can be photographed for later review.

\section{PLACENTA AND UMBILICAL CORD}

These structures are of course part of the conceptus and it is often overlooked that examining them can help to establish the sequence of events leading to perinatal death. For example, it may show the cause (and give an estimate of the time of onset) of hypoxic/ ischaemic insults. There may be evidence of 
ascending or haematogenous infection, and specific organisms can be identified using special staining techniques, immunochemistry, and in situ hybridisation. Assessment of chorionicity is clearly important in multiple pregnancy. Histological examination of the placenta may give the first clue to an underlying inborn error of metabolism. ${ }^{6}$ Fibroblasts prepared from placental tissue can be used for metabolic studies as well as cytogenetic investigations, and provide a source of DNA for molecular biological studies.

Therefore after perinatal death (and also when infants are born alive but in poor condition), the placenta and cord should wherever possible be sent for pathological examination. Increasingly, the findings are required to resolve issues raised during medicolegal investigation.

\section{RADIOGRAPHY}

Many pathology departments providing a perinatal pathology service now have dedicated $x$ ray cabinets for radiography. This allows a variety of skeletal and soft tissue abnormalities to be identified, many of which are not readily detectable by any other method (table 1).

The appearance of ossification centres and measurement of long bone lengths can give a rough guide to gestational age, particularly after 24 weeks gestation, and this is helpful when the more precise information available from internal examination (cerebral gyral development, organ histology) is not available. ${ }^{58}$ Refinements to these methods have been suggested in recent papers ${ }^{8-10}$ and require further evaluation.

Table 2 summarises the findings from reported series of fetal and infant postmortem radiography. Most reports are largely descriptive and all except one hospital based. The proportion of cases with radiological abnormalities varies considerably from series to series, depending partly on the degree of case selection and also on whether non-skeletal abnormalities are included. In several reports, ${ }^{15}{ }^{17-20}$ an attempt is made to quantify the clinical value of the examination, but only Olsen et al ${ }^{20}$ attempt to provide reproducible criteria (in their series, the degree to which the abnormality specifically informs the cause of death). Four papers have compared cases with and without external malformations ${ }^{13-15}{ }^{20}$; not surprisingly more skeletal abnormalities occur in the former group, and Grisom and Driscoll ${ }^{13}$ and Cremin and Draper ${ }^{14}$ recommend restricting radiography to these cases.

Table 1 Information provided by postmortem radiology

- Gestational age assessment

- Skeletal malformation

(a) dysplasia

(b) dysostoses (eg defects of limbs, ribs, vertebrae)

- Skeletal trauma (birth, other)

- Other bone disease (eg infection, metabolic bone disease of prematurity)

- Extraskeletal mineralisation, for example

- Inspissated intestinal contents (secondary to obstruction)

- Hepatic calcification (hypoxia, infection, etc)

- Meconium peritonitis

Idiopathic arterial calcification of infancy

- Abnormal gas accumulations, for example - Body cavities

- Pulmonary interstitial emphysema

- Surgical emphysema

- Intravascular

- Necrotising enterocolitis

- Positioning of cannulae, drains, etc

- Additional information from contrast radiography

- Definitive record of skeletal morphology
However, the autopsy rates (where stated) in table 2 are very high ( $100 \%$ in many), and only one paper has tried to specifically assess the value of radiography when internal organ examination is declined: Winter and Sandin ${ }^{15}$ reported that the radiograph "aided assessment" in six of 100 cases where there was both no autopsy and no external malformation. Clearly, if malformations are noted externally, radiographs can show the type and extent of any associated skeletal abnormality; for many skeletal dysplasias radiology is the single most important diagnostic investigation. ${ }^{21}{ }^{22}$ But even if there are no external dysmorphic features, when autopsy is declined, radiography will exclude most skeletal abnormalities and (as table 1 suggests) may provide important clues to the underlying disease processes. As an example, vertebral body anomalies are associated with malformations of other organs such as the heart. ${ }^{23}$ In their study of 137 consecutive perinatal autopsies, Gronvall and Graem ${ }^{19}$ noted "major" radiological abnormalities in $12(9 \%)$, including anomalies of spinal vertebral bodies in eight cases, of which five had malformations of other internal organs; only three of the eight showed external dysmorphism.

To conclude, consent for radiography should be sought in all cases where standard autopsy is declined.

\section{CONTRAST RADIOGRAPHY}

This technique has been used to show a variety of internal malformations, particularly those involving the heart and vessels. ${ }^{12}{ }^{15}{ }^{194-26}$ Although it is time consuming and presents challenges in execution and interpretation (and because of this is perhaps underused), it should be considered when full autopsy is declined and malformation is suspected, particularly when other imaging modalities such as MRI are not available.

\section{ULTRASOUND AND COMPUTED TOMOGRAPHY SCANNING}

Although ultrasound is widely used in life, particularly for the assessment of neonatal central nervous system pathology, there have been few studies of its use after death. In a descriptive report of perinatal cases, Furness $e t a^{27}$ noted the potential for delineating internal anatomy and guiding needle biopsy. Farina et al ${ }^{28}$ recently reported their experience using a combination of ultrasound and ultrasound guided needle biopsy in 100 adult autopsies and claim an $83 \%$ concordance rate with standard autopsy for the cause of death or main pathological diagnosis; the value of this approach after perinatal death remains to be fully evaluated.

There do not appear to have been any systematic studies of the use of computed tomography scanning as an alternative to standard perinatal (or adult) autopsy.

\section{MRI}

MRI produces high resolution images of internal organs and is therefore potentially valuable in postmortem investigation. Four prospective studies have correlated MRI and standard perinatal autopsy findings.

The feasibility of the method was shown by Ros et $a l^{29}$ in examinations of three stillbirths, one neonatal death, and two adult deaths. Brookes $e a^{30}$ examined a series of 20 cases including miscarriages, terminations for malformation, stillbirths, and neonatal deaths. They detected a variety of macroscopic lesions, and highlighted the potential advantages of MRI in delineating major abnormalities of the central nervous system in situ when, for example, autolytic softening has made routine autopsy examination technically difficult. Although MRI and standard autopsy were said to be "of similar clinical significance" in 18 of the 20 cases (90\%), the validity of this claim is doubtful because it is based on the incorrect assumption that MRI and standard autopsy provide 
Table 2 Studies of perinatal postmortem radiography

\begin{tabular}{|c|c|c|c|c|}
\hline Study & Case selection & Autopsy rate & Case mix & Radiographs with abnormalities \\
\hline Ryan \& Kozlowski" & 109 consecutive radiographs & Not stated & SB, NND & Skeletal $17 \%$ \\
\hline Foote et $a l^{12}$ & 2500 consecutive deaths & Not stated & $\mathrm{SB}, \mathrm{NND}$ & $18 \%$ \\
\hline Griscom \& Driscoll ${ }^{13}$ & $\begin{array}{l}\text { Series A (unselected): } 238 \text { series B } \\
\text { (selected): } 102\end{array}$ & Not stated & $\begin{array}{l}\text { Fetal ( } 20 \text { weeks-term), } \\
\text { NND }\end{array}$ & $18 \%($ series $A), 75 \%$ (series $B$ ) \\
\hline Cremin \& Draper $^{14}$ & 100 consecutive deaths & $89 \%$ & $\mathrm{SB}, \mathrm{NND}$ & Not stated \\
\hline Winter \& Sandin ${ }^{15}$ & 488 consecutive deaths & $77 \%$ & $\mathrm{SB}, \mathrm{NND}$ & $\begin{array}{l}\text { Soft tissue } 21 \% \text {, skeletal } 18 \% \text {, } \\
\text { "useful or diagnostic" } 16 \%\end{array}$ \\
\hline Seppanen $^{16}$ & 514 consecutive radiographs & $100 \%$ & $\mathrm{SB}, \mathrm{NND}$ & $30 \%$ \\
\hline de la Fuente et $a l^{17}$ & 234 consecutive autopsies & $100 \%$ & $\begin{array}{l}\text { Fetal ( } 14 \text { weeks-term), } \\
\text { NND }\end{array}$ & $21 \%$, "essential" $2.1 \%$ \\
\hline Kalifa et $a l^{8}$ & 400 consecutive deaths & Not stated & Fetal ( 11 weeks-term) & $\begin{array}{l}\text { "Valuable for diagnosis" 13.5\%, } \\
\text { "additional information" 34.5\% }\end{array}$ \\
\hline Gronvall \& Graem ${ }^{19}$ & 137 consecutive autopsies & $100 \%$ & $\begin{array}{l}\text { Fetal (8 weeks-term), } \\
\text { NND }\end{array}$ & $59 \%$, "major" 9\% \\
\hline Olsen et $a^{20}$ & 542 consecutive deaths & $100 \%$ & $\begin{array}{l}\text { Fetal ( } 16 \text { weeks-term), } \\
\text { NND }\end{array}$ & $30 \%$, "vital" $3.1 \%$ \\
\hline
\end{tabular}

the same level of diagnostic information. For example, a report of negative findings at standard autopsy means that infection, hypoxic injury, organ dysplasia, and metabolic disease have been excluded, but negative findings at MRI do not allow similar conclusions to be drawn.

The other two studies focused on the identification of malformations. Woodward et $a l^{31}$ examined 26 consecutive fetuses and neonates. All underwent standard autopsy, which showed 47 major and 11 minor malformations ("minor" included anomalies such as horseshoe kidney and annular pancreas). MRI films were reviewed independently by three radiologists, all of whom identified 37 of the major malformations (detection rate $79 \%$ ) and one of the minor malformations (detection rate $9.1 \%$ ). One radiologist had a detection rate of $91 \%$ for the major malformations. Four major anomalies not identified by any of the reviewers were hypoplastic left heart, tetralogy of Fallot, ileocaecal valve atresia, and oesophageal atresia. Six false positive MRI diagnoses were made. The potential benefits of MRI in showing macroscopic abnormalities of the central nervous system were again noted.

In the most recent study, ${ }^{32} 10$ consecutive fetuses were examined after termination of pregnancy for malformation. MRI and autopsy both confirmed the major antenatal ultrasound findings that had prompted the decision to terminate the pregnancy. Autopsy provided additional information in six cases, which informed risk counselling in two. Two other recent small series $(n<10)$ have compared MRI and autopsy in adult deaths..$^{34}$

These studies suggest that MRI has a potential role in confirming, detecting, or excluding major malformations and other relatively large structural abnormalities, and may be particularly helpful in assessing malformations of the central nervous system. Identifying cardiovascular anomalies has proved problematic, ${ }^{30} 31$ although improvements may come through technical advances such as three dimensional MRI. ${ }^{35}{ }^{36}$ However, as postmortem MRI does not identify all malformations and does not detect the changes at a histological level that are the hallmark of many perinatal diseases (infection, hypoxia, organ dysplasia, metabolic disease, etc), it cannot be used as a substitute for standard autopsy. Its value in assessing cases when there is an advanced degree of autolysis/maceration (a common situation) is also unknown. Definitive assessment of the value of MRI awaits studies comparing it with standard autopsy in large series that include the full spectrum of perinatal disease, perhaps in combination with needle biopsy of internal organs. Of course, the availability of MRI services is another important consideration: many departments are simply not in a position to offer this facility after death.

\section{LIMITED AUTOPSY AND LAPAROSCOPIC AUTOPSY}

Families may be willing to give consent to standard autopsy that is restricted to certain parts of the body. For example, examination of the thoracic contents will allow confirmation of cardiovascular malformations or the presence of pneumonia or other lung disease. Specific diagnostic concerns can therefore be resolved in this way, but it always has to be borne in mind that pathological processes in the perinatal period (such as malformation) very often involve multiple organ systems.

An alternative approach used in adult postmortem investigation is the use of endoscopes or laparoscopes. In addition to case reports, a small number of centres have described their experience with this technique in autopsy series. ${ }^{37-39}$ When standard autopsy consent is withheld, it allows detection and guided biopsy of macroscopic abnormalities visible within body cavities or hollow viscera. There are no reports of its use in the perinatal period, and clearly there are technical issues to be considered, but there may be potential benefit in selected cases of perinatal loss.

\section{SKIN BIOPSY, NEEDLE BIOPSY, AND ASPIRATION OF BODY FLUIDS}

Fibroblasts cultured from skin and placenta can be used for cytogenetic and metabolic studies. Many units now have protocols for handling the tissue samples, which should be refrigerated (not frozen) if there is likely to be a delay in their despatch-for example, over a weekend.

Trucut biopsies or open biopsies through small incisions, particularly from large accessible organs such as liver or lungs, may allow diagnostic histological or metabolic studies; this can be combined with aspiration of blood, cerebrospinal fluid, urine, or other fluids for microbiological and metabolic investigations. ${ }^{28}{ }^{40-42}$ However, reported series of such "needle autopsies" do not include perinatal deaths, where a more widespread sampling of internal organs for histological examination would be required to adequately assess gestational age, infection, dysplasia, etc. Given the small size of many of the organs, the practicality and value of this approach (perhaps in combination with MRI) remains to be evaluated, but biopsy of individual organs clearly has a role in selected cases.

Where there is a strong clinical suspicion of metabolic disease, the case should be discussed with a metabolic physician or appropriate laboratory staff to obtain advice on 
the locally preferred tissue or fluid samples. As a minimum, the following are suggested ${ }^{43}{ }^{44}$ : blood (spots on Guthrie card for acylcarnitines; frozen plasma; frozen EDTA sample for DNA); frozen urine; frozen liver and muscle; skin for fibroblast culture.

\section{CONCLUSIONS}

- Standard autopsy provides the only means of fully investigating fetal loss, stillbirth, and neonatal death, and it is a family's right to have the opportunity to give consent.

- Restricting the autopsy to particular body cavities or organs limits the information available but allows specific questions to be addressed and may be more acceptable to some families.

- When families do not wish to give consent for any direct macroscopic and histological examination of the internal organs, valuable information for counselling and audit may be obtained from external examination, placental/ cord examination, radiology, and, in selected cases, MRI, tissue biopsy, and aspiration of body fluids.

- Radiology should be undertaken if possible in all cases where full autopsy is declined, and is particularly important when there is obvious or suspected malformation.

- MRI can detect some malformations and other macroscopic lesions. It cannot, however, function as a substitute for standard autopsy.

- If the clinical history suggests a possible metabolic disease, tissue and fluid samples may allow diagnosis.

- If in doubt, discuss the case with a perinatal pathologist!

\section{ACKNOWLEDGEMENTS}

Thanks to Dr Alan Fenton for his comments on the manuscript.

\section{Authors' affiliations}

C Wright, Department of Pathology, Royal Victoria Infirmary, Newcastle upon Tyne, UK

R E J Lee, Department of Radiology, Royal Victoria Infirmary

\section{REFERENCES}

1 Gordiin SJ, Erwich JJHM, Khong TY. Value of the perinatal autopsy: critique. Pediatr Dev Pathol 2002;5:480-8.

2 Chiswick M. Perinatal and infant postmortem examination. BMJ 1995;310:141-2.

3 Turner J, Raphael B. Requesting necropsies. BMJ 1997;314:1499-500.

4 Maternal and Child Health Research Consortium. Confidential Enquiry into Stillbirths and Deaths in Infancy. 8th annual report. London: Maternal and Child Health Research Consortium, 2001.

5 Valdes-Dapena M, Kalousek DK, Huff DS. Perinatal, fetal and embryonic autopsy. In: Gilbert-Barness E, ed. Potter's pathology of the fetus and infant. St Louis: Mosby, 1997:483-524.

6 Dimmick JE, Applegarth DA, Vallance HD. Inborn metabolic disease of the perinatal infant. In: Wigglesworth JS, Singer DB, eds. Textbook of fetal and perinatal pathology. Boston: Blackwell Science, 1998:512-52.

7 van der Harten HJ, Brons JT, Schipper NW, et al. The prenatal development of the normal human skeleton: a combined ultrasonographic and post-mortem radiographic study. Pediatr Radiol 1990;21:52-6.

8 Olsen OE, Lie RT, Maartmann-Moe H, et al. Skeletal measurements among infants who die during the perinatal period: new population-based reference. Pediatr Radiol 2002;32:667-73.

9 Stempfle N, Huten Y, Fondacci C, et al. Fetal bone age revisited: proposal of a new radiographic score. Pediatr Radiol 1995;25:551-5.
10 Olsen OE, Lie RT, Lachmann RS, et al. Ossification sequence in infants who die during the perinatal period: population-based references. Radiology 2002;225:240-4

11 Ryan J, Kozlowski K. Radiography of stillborn infants. Aust Radiol 1971; 15:213-26.

12 Foote GA, Wilson AJ, Stewart JH. Perinatal post-mortem radiography: experience with 2500 cases. Br J Radiol 1978;51:351-6.

13 Griscom NT, Driscoll SG. Radiography of stillborn fetuses and infants dying at birth. AJR Am J Roentgenol 1980;134:485-9.

14 Cremin BJ, Draper R. The value of radiography in perinatal deaths. Pediatr Radiol 1981;11:143-6.

15 Winter RM, Sandin BM. The radiology of stillbirths and neonatal deaths. Br J Obstet Gynaecol 1984;91:762-5.

16 Seppanen U. Perinatal postmortem radiography. Acta Radiol 1986;27:481-94

17 de la Fuente AA, Dornseiffen G, van Noort G, et al. Routine perinatal postmortem radiography in a peripheral pathology laboratory. Virchows Arch A Pathol Pathol Anat 1988:413:513-19.

18 Kalifa G, Barbet JP, Labbe F, et al. Value of systematic post mortem radiographic examinations of fetuses: 400 cases. Pediatr Radiol 1989;19:111-13

19 Gronvall J, Graem N. Radiography in post-mortem examinations of fetuses and neonates. APMIS 1989;97:274-80.

20 Olsen OE, Espeland A, Maartmann-Moe H, et al. Diagnostic value of radiography in cases of perinatal death: a population based study. Arch Dis Child Fetal Neonatal Ed 2003;88:F521-4.

21 van der Harten HJ. The skeletal system. In: Keeling J, ed. Fetal and neonatal pathology. London: Springer, 2001:685-709.

22 Yang SS. The skeletal system. In: Wigglesworth JS, Singer DB, eds. Textbook of fetal and perinatal pathology. Boston: Blackwell Science, 1998:1039-82.

$23 \mathrm{Scott} \mathrm{CI}$. Pectoral girdle, spine, ribs and pelvic girdle. In: Stevenson RE, Hall JG, Goodman RM, eds. Human malformations and related anomalies. Oxford: Oxford University Press, 1993:655-98.

24 Richter E. Postmortem angiocardiography in newborn infants with congenital malformations of the heart and great vessels. Pediatr Radiol 1976;4:133-8.

25 Russell GA, Berry PJ. Post mortem radiology in children with congenital heart disease. J Clin Pathol 1988;41:830-6.

26 Hawass N, al-Badawi MG, Fatani JA, et al. Fetal necrogram: a new technique. Experience with 12000 contrast examinations. Invest Radiol 1989;24:711-20.

27 Furness ME, Weckert RC, Parker SA, et al. Ultrasound in the perinatal autopsy. J Med Genet 1989;26:368-72.

28 Farina J, Millana C, Fdez-Acenero MJ, et al. Ultrasonographic autopsy (echopsy): a new autopsy technique. Virchows Arch 2002;440:635-9.

29 Ros PR, King CL, Vo P, et al. Preautopsy magnetic resonance imaging: initial experience. Magn Reson Imaging 1990;8:303-8.

30 Brookes JAS, Hall-Craggs MA, Sams VR, et al. Non-invasive perinatal necropsy by magnetic resonance imaging. Lancet 1996;348:1139-41.

31 Woodward PJ, Sohaey R, Harris DP, et al. Postmortem fetal MR imaging: comparison with findings at autopsy. AJR Am J Roentgenol 1997;168:41-6.

32 Huisman TAGM, Wisser J, Stallmach T, et al. MR autopsy in fetuses. Fetal Diagn Ther 2002;17:58-64.

33 Patriquin L, Kassarjian A, O'Brien M, et al. Postmortem whole-body magnetic resonance imaging as an adjuct to autopsy: preliminary clinical experience. J Magn Reson Imaging 2001;13:277-87.

34 Bisset RAL, Thomas RB, Turnbull IW, et al. Postmortem examinations using magnetic resonance imaging: four year review of a working service. BMJ 2002;324:1423-4.

35 Deng J, Brookes JAS, Gardener JE, et al. Three-dimensional magnetic resonance imaging of the postmortem fetal heart. Fetal Diagn Ther 1996;11:417-21.

36 Brookes JAS, Deng J, Wilkinson ID, et al. Three-dimensional imaging of the postmortem fetus by MRI: early experience. Fetal Diagn Ther 1999;14:166-71

37 Avrahami R, Watemberg S, Hiss $Y$, et al. Laparoscopic vs conventional autopsy. A promising perspective. Arch Surg 1995; 130:407-9.

38 Avrahami R, Watemberg S, Hiss Y. Thoracoscopy vs conventional autopsy of the thorax. A promising perspective. Arch Surg 1995;130:956-8.

39 Cacchione RN, Sayad P, Pecoraro AM, et al. Laparoscopic autopsies. Surg Endosc 2001;15:619-22.

40 Underwood JCE, Slater DN, Parsons MA. The needle necropsy. BM 1983;286: 1632-4.

41 Faroudi F, Cheung K, Duflou J. A comparison of the needle biopsy post mortem with the conventional autopsy. Pathology 1995;27:79-82.

42 Huston BM, Malouf NN, Azar HA. Percutaneous needle autopsy sampling. Mod Pathol 1996;9:1101-7.

43 Fitzpatrick D. Genetic metabolic disease. In: Keeling J, ed. Fetal and neonatal pathology. London: Springer, 2001:153-74.

44 Leonard JV, Morris AAM. Inborn errors of metabolism around the time of birth. Lancet 2000;356:583-7. 